OPEN ACCESS

Edited by:

Miklos Fuzi,

Semmelweis University, Hungary

Reviewed by:

Pak-Leung Ho,

The University of Hong Kong,

Hong Kong

Hanna Evelina Sidjabat

The University of Queensland,

Australia

*Correspondence:

Ruichao L

rchl88@yeah.net

Zhiqiang Wang

zqwang@yzu.edu.cn

${ }^{\dagger}$ These authors have contributed equally to this work

Specialty section:

This article was submitted to

Antimicrobials, Resistance and Chemotherapy,

a section of the journal

Frontiers in Microbiology

Received: 01 July 2019

Accepted: 15 August 2019

Published: 04 September 2019

Citation:

Liu Z, Xiao X, Li Y, Liu Y, Li R and Wang $Z$ (2019) Emergence of IncX3

Plasmid-Harboring bla ${ }_{N D M-5}$ Dominated by Escherichia coli ST48 in a Goose Farm in Jiangsu, China.

Front. Microbiol. 10:2002.

doi: 10.3389/fmicb.2019.02002

\section{Emergence of IncX3}

\section{Plasmid-Harboring bla $\mathrm{NDM}_{-5}$} Dominated by Escherichia coli ST48 in a Goose Farm in Jiangsu, China

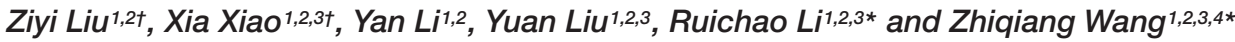 \\ ${ }^{1}$ College of Veterinary Medicine, Yangzhou University, Yangzhou, China, ${ }^{2}$ Jiangsu Co-innovation Center for Prevention \\ and Control of Important Animal Infectious Diseases and Zoonoses, Yangzhou, China, ${ }^{3}$ Institute of Comparative Medicine, \\ Yangzhou University, Yangzhou, China, ${ }^{4}$ Institutes of Agricultural Science and Technology Development, Yangzhou, China
}

Twelve carbapenem-resistant Escherichia coli strains were obtained from goose farms in Jiangsu, China. These isolates were resistant to multiple antimicrobials, and positive for the bla $a_{\mathrm{NDM}-5}$. The carbapenem-resistance of all strains mediated by bla $\mathrm{NDM}_{-5}$ were successfully conjugated to E. coli J53. S1-PFGE and WGS results showed bla NDM -5 was located on IncX3 conjugative plasmids with a size of ca. $46 \mathrm{~kb}$. All bla $\mathrm{NDM}-5$-bearing IncX3 plasmids shared the same genetic context almost identical to pNDM_MGR194-

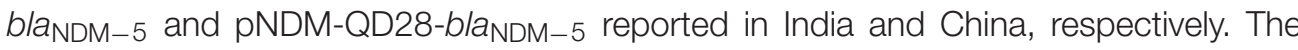
twelve strains belonged to three STs, in which the dominant type of $E$. coli isolated from breeding goose farm carrying bla $a_{\mathrm{NDM}-5}$ was ST48. The emergence of bla $\mathrm{NDM}_{-5}$-bearing strains in goose farms and the clonal transmission of $E$. coli within the breeding goose farm highlighted the potential reservoir of carbapenemase genes in waterfowl farming system, which may further contaminate environments and pose a threat to public health. Comprehensive surveillance of carbapenem-resistant bacteria in goose farms warrants further study to evaluate the underlying risks.

Keywords: carbapenemase genes, bla ${ }_{\mathrm{NDM}-5}$, E. coli, long-read sequencing, plasmids

\section{INTRODUCTION}

Enterobacteriaceae such as Escherichia coli, Klebsiella pneumoniae and Salmonella spp. are important pathogens that cause human infections. Carbapenemase-producing Enterobacteriaceae (CPE) is constantly reported worldwide and has become an urgent public health threat (Potter et al., 2016). So far, CPE has been detected in animals, environment and vegetable samples that are closely related to humans (Walsh et al., 2011; Wang J. et al., 2018; Wang R.B.et al., 2018). As one main type of carbapenemases, New Delhi metallo- $\beta$-lactamase (NDM) is able to confer resistance to almost all $\beta$-lactams. Since the first report of bla $a_{\mathrm{NDM}-1}$ in 2009, 21 variants of NDM enzymes (NDM-1 to NDM-21) have been reported (Yong et al., 2009; Liu et al., 2018). Among them, the NDM-5-encoding gene, bla $a_{\mathrm{NDM}-5}$, was first reported in an $E$. coli recovered from a patient in the United Kingdom (Hornsey et al., 2011). In China, a lot of studies have reported the bla $_{\mathrm{NDM}-5}$ in Enterobacteriaceae of animal origin. Regarding poultry origin, there was one report of the presence of NDM in Enterobacteriaceae in the poultry production environment, which may 
indicated that $b l a_{\mathrm{NDM}-5}$ has been widely distributed among Enterobacteriaceae in poultry farms (Zhang et al., 2019). Especially, the coexistence of bla $a_{\mathrm{NDM}-5}$ and mcr-1 in E. coli of single duck origin has also been reported, which raised the public concern about the antibiotic resistance of waterfowl (Yang et al., 2016).

In addition to duck origin, goose breeding industry is particularly developed in Jiangsu, China. The breeding mode of geese in farms is different from other poultry farms, because many pools are built in goose farms to support their growth. Owing to the use of antibiotics and possible dissemination of resistant bacteria via water system in goose farms, the antibiotic resistance may be extremely complicated. However, there are few reports of antibiotic resistance in goose farms. Therefore, enhancing the surveillance of antibiotic resistance in goose farms is necessary. To cover this gap, we investigated the prevalence of bla $a_{\mathrm{NDM}-5}$-positive $E$. coli isolates in goose farms and probed the genomic features of these isolates with cutting-edge nanopore long-read sequencing technology.

\section{MATERIALS AND METHODS}

\section{Identification of Bacterial Strains and Detection of Carbapenemase Genes}

A total of 117 samples, including anal swab, feed, feces, water and soil, were collected within one day from a breeding goose farm $(n=68)$ and a goose hatchery $(n=49)$ in Jiangsu Province, China in 2018 (Table S1). There are about 10 goose houses in the breeding farm where farming scale approaches to one thousand. We randomly selected three goose houses as sample sites. It was worth pointing out that we considered the samples collected from the three goose houses as related samples due to the same feed and water used in different goose houses, the open environment and the free movement of the breeders. The hatchery farm which isolated from outside had some distance away from the breeding goose farm (Figure S7). Both farms belonged to the same goose producing chain meaning that the goslings from hatchery were transported to the breeding farm for feeding. To be note, the breeding goose were mainly for food and the water supply of the goose farm was from the river outside the farm. Besides, there were no hospitals, factories or other source of pollutions near the farm. Isolation of carbapenem-resistant $E$. coli was performed as following method. Briefly, each sample was added to $3 \mathrm{~mL}$ of buffer peptone water (BPW) and incubated for $6-8 \mathrm{~h}$ in $37^{\circ} \mathrm{C}$, followed by inoculating into Mossel Enterobacteria enrichment broth (MEE broth) with $0.5 \mathrm{mg} / \mathrm{L}$ meropenem for $6 \mathrm{~h}$. The carbapenemresistant bacteria were isolated by streaking on MacConkey plates containing $2 \mathrm{mg} / \mathrm{L}$ meropenem and identified by MALDITOF MS and 16S rDNA sequencing (Kim et al., 2010). In this way, significant number of well-formed carbapenem-resistant colonies were grown on MacConkey plates, but only one colony was selected for further investigations. The carbapenemresistant isolates were screened for the most found $\beta$-lactamases genes including the OXA-1-like broad-spectrum $\beta$-lactamases, extended-spectrum $\beta$-lactamases (ESBLs), plasmid-mediated
AmpC $\beta$-lactamases and class A, B and D carbapenemases using multiplex PCR assays reported previously (Dallenne et al., 2010). The complete coding sequence of $b a_{\mathrm{NDM}-5}$ was amplified with the primers (NDM-up, 5'-CTTCCAACGGTTTGATCGTC; NDM-dw, 5'-ATTGGCATAAGTCGCAATCC) and confirmed by $\mathrm{ABI} 3730$ sequencing.

\section{Antimicrobial Susceptibility Testing, Conjugation Assay and S1-PFGE}

The MICs of bla $a_{\mathrm{NDM}-5}$-positive E. coli isolates against antibiotics (Table 1), as well as their transconjugants, were determined using the microdilution broth method and interpreted according to CLSI (2014) guidelines. E. coli strain ATCC 25922 was used as the quality control. To investigate transferability of $b l a_{\mathrm{NDM}-5}$, conjugation assay was performed for the twelve $b l a_{\mathrm{NDM}-5}$ positive $E$. coli isolates with the sodium azide-resistant E. coli $\mathrm{J} 53$ as the recipient strain. Overnight culture of donor strains and E. coli 553 were mixed (ratio of 1:4) in LB broth, then subjected to overnight incubation on LB agar plates. The

TABLE 1 | Antibiotic susceptibility profiles of the carbapenem-resistant $E$. coli strains and the corresponding transconjugants to different antibiotics (mg/L).

\begin{tabular}{|c|c|c|c|c|c|c|c|c|c|}
\hline \multirow[t]{2}{*}{ Isolates } & \multicolumn{9}{|c|}{ Antibiotics $^{a}$} \\
\hline & MEM & STR & ATM & AMX & CQM & FFC & DOX & ENR & CL \\
\hline L33 & 128 & 128 & 256 & $>64$ & $>128$ & $>64$ & 32 & 16 & 1 \\
\hline L37 & 128 & 64 & 32 & $>64$ & $>128$ & $>64$ & 16 & 16 & 1 \\
\hline Ł41-1 & 128 & 16 & 4 & $>64$ & $>128$ & $>64$ & 32 & $\leq 0.125$ & 1 \\
\hline L43-1 & 256 & 32 & 8 & $>64$ & $>128$ & $>64$ & 32 & 0.25 & 1 \\
\hline L53 & 128 & 128 & 256 & $>64$ & $>128$ & $>64$ & 32 & 4 & 1 \\
\hline L56 & 128 & $>128$ & $>256$ & $>64$ & $>128$ & $>64$ & 16 & 8 & 1 \\
\hline L65 & 128 & 1 & $\leq 0.5$ & $>64$ & $>128$ & $>64$ & 32 & 1 & 1 \\
\hline L99 & 128 & $>128$ & $>256$ & $>64$ & $>128$ & $>64$ & 32 & 4 & 1 \\
\hline L100 & 128 & 64 & 32 & $>64$ & $>128$ & $>64$ & 32 & $\leq 0.125$ & 0.5 \\
\hline L102 & 128 & 32 & 8 & $>64$ & 128 & 4 & 16 & $\leq 0.125$ & 1 \\
\hline L103-1 & 64 & 128 & $>256$ & $>64$ & $>128$ & $>64$ & 16 & 8 & 0.125 \\
\hline L103-2 & 128 & 64 & 256 & $>64$ & $>128$ & $>64$ & 16 & $\leq 0.125$ & 1 \\
\hline L33T & 128 & 1 & $\leq 0.5$ & $>64$ & 128 & 8 & 4 & $\leq 0.125$ & 0.5 \\
\hline L37T & 32 & 1 & $\leq 0.5$ & $>64$ & 128 & 8 & 4 & $\leq 0.125$ & 0.5 \\
\hline L41-1T & 64 & 0.5 & 2 & $>64$ & $>128$ & 4 & 8 & $\leq 0.125$ & 0.5 \\
\hline L43-1T & 64 & 1 & 1 & $>64$ & $>128$ & 8 & 8 & $\leq 0.125$ & 0.25 \\
\hline L53T & 128 & 1 & 64 & $>64$ & 128 & 8 & 4 & $\leq 0.125$ & 1 \\
\hline L56T & 64 & 1 & $\leq 0.5$ & $>64$ & 128 & 4 & 4 & $\leq 0.125$ & 0.5 \\
\hline L65T & 64 & 1 & $\leq 0.5$ & $>64$ & 128 & 4 & 2 & $\leq 0.25$ & 0.5 \\
\hline L99T & 64 & 2 & $\leq 0.5$ & $>64$ & 64 & 4 & 2 & $\leq 0.125$ & 1 \\
\hline L100T & 64 & 1 & 2 & $>64$ & 128 & 4 & 2 & $\leq 0.125$ & 1 \\
\hline L102T & 128 & 1 & 1 & $>64$ & $>128$ & 4 & 4 & $\leq 0.125$ & 0.5 \\
\hline L103-1T & 128 & 1 & $\leq 0.5$ & $>64$ & 128 & 8 & 4 & $\leq 0.125$ & 1 \\
\hline L103-2T & 64 & 1 & 64 & $>64$ & 128 & 4 & 8 & $\leq 0.125$ & 1 \\
\hline $\mathrm{J} 53^{\mathrm{b}}$ & $\leq 0.25$ & 1 & $\leq 0.5$ & 1 & $\leq 0.25$ & 4 & 4 & $\leq 0.125$ & 0.5 \\
\hline ATCC25922 & $\leq 0.25$ & 0.5 & $\leq 0.5$ & 1 & $\leq 0.25$ & 2 & 0.5 & $\leq 0.125$ & 0.5 \\
\hline
\end{tabular}

a MEM, meropenem; STR, streptomycin; ATM, aztreonam; AMX, amoxicillin; CQM, cefquinome; FFC, florfenicol; DOX, doxycycline; ENR, enrofloxacin; CL, colistin. All susceptibility tests were repeated at least three times according to CLSI method. The results of colistin susceptibility were interpreted according to EUCAST breakpoints. ${ }^{b}$ recipient strain. ${ }^{c}$ quality control strain. 
mixture culture was then diluted and spread on a selective $\mathrm{LB}$ agar plate supplemented with meropenem $(2 \mathrm{mg} / \mathrm{L})$ and sodium azide $(200 \mathrm{mg} / \mathrm{L})$ to recover transconjugants. Carriage of bla $a_{\mathrm{NDM}-5}$ in the transconjugant was confirmed by PCR and MICs. The frequencies of conjugation transfer of five $b l a_{\mathrm{NDM}-5}$ plasmids were conducted and expressed as transconjugants per donor cell (T/D) as previously described (Zhong et al., 2012). S1-PFGE was performed to obtain plasmid profiles in donor strains and transconjugants, and the Salmonella enterica serotype Braenderup H9812 was used as the standard size marker.

\section{DNA Extractions, WGS and Bioinformatics Analysis}

Genomic DNA of the twelve carbapenem-resistant strains were prepared using the TIANamp Bacteria DNA Kit (Tiangen, China) and subjected to WGS using the Illumina HiSeq 2500 platform (Illumina, San Diego, CA, United States) generating $2 \times 150 \mathrm{bp}$ paired-end reads (1 Gbp per sample). The software SPAdes (v3.11.1) was utilized to assemble the genomes. Furthermore, genomes of six strains (L37, L41-1, L53, L65, L100, and L103-2) belonging to different clonal groups based on Illumina data were selected for MinION long-read sequencing (400 Mbp per sample) with the Rapid Barcoding Kit RBK004 without size selection to obtain the complete genome sequences according to the published method ( $\mathrm{Li} \mathrm{R}$. et al., 2018). Briefly, de novo assembly with hybrid strategy combining Illumina short-read data and MinION long-read data was performed with unicycler (v0.4.4) as the reported method (Wick et al., 2017; Li R. et al., 2018). Sequence Types (STs) and antimicrobial resistance genes were determined using the GoSeqIt tool ${ }^{1}$. Plasmid replicon type and plasmid multi-locus STs were determined using the PlasmidFinder and pMLST tools ${ }^{2}$. The complete genome sequences were annotated using the RAST ${ }^{3}$ automatically and modified manually. Comparisons between bla $a_{\mathrm{NDM}-5}$-bearing plasmids and homologous plasmid sequences available in NCBI database were performed using the BRIG tool and Easyfig (Alikhan et al., 2011; Sullivan et al., 2011). The phylogenetic tree based on SNPs was generated as previously reported (Li et al., 2017).

The complete genome sequences of the six strains were deposited in NCBI database with the accession numbers listed in Table 2. The de novo assembled results of another six strains were deposited in figshare database $e^{4}$ for reference.

\section{RESULTS AND DISCUSSION}

\section{Characterization of Carbapenem-Resistant E. coli Strains}

Twelve carbapenem-resistant E. coli strains were isolated from the 117 samples. The twelve carbapenem-resistant E. coli strains included seven strains (58.3\%) from anal swab samples (L33,

${ }^{1}$ https://tools.goseqit.com/

${ }^{2}$ http://www.genomicepidemiology.org/

${ }^{3}$ http://rast.nmpdr.org/

${ }^{4}$ https://figshare.com/articles/L33-L103-1/8044847
L37, L99, L100, L102, L103-1, L103-2), two strains (16.7\%) from water samples (L53, L56), two isolates (16.7\%) from fecal samples (L43-1, L65) and one isolate (8.3\%) from a feed sample (L41-1). Among them, L65 was isolated from goose hatchery, while the other eleven strains were isolated from the breeding goose farm indicating the occurrence of carbapenem-resistant strains of breeding goose farm was more prevalent. These strains were resistant to multiple antibiotics including meropenem, streptomycin, amoxicillin, cefquinome, florfenicol and doxycycline, but most of them were susceptible to enrofloxacin (Table 1).

All the carbapenem-resistant $E$. coli strains harbored $b l a_{\mathrm{NDM}-5}$. The strains were also found to carry multiple resistance genes conferring resistance to $\beta$-lactam $\left(b l a_{\mathrm{CTX}-\mathrm{M}}\right.$, bla $\left.a_{\mathrm{TEM}-1}, \quad b l a_{\mathrm{OXA}}\right)$, aminoglycoside $(\operatorname{str} A, \operatorname{str} B, \operatorname{aac}(3)-I I d$, $\left.a p h(6)-I d, a p h\left(3^{\prime \prime}\right)-I b, r m t B\right)$ fosfomycin (fosA), tetracycline (tet $(\mathrm{A}))$, phenicols (cmlA1, floR), quinolone (qnrS1), sulfonamide(sul2), rifampicin (arr-2) and trimethoprim (dfrA14) (Table 2). Moreover, the twelve E. coli isolates were categorized into two STs and one novel ST according to WGS data. Ten strains belonged to ST48 and one novel ST (ST8809) strain (L103-2) was isolated from the breeding goose farm, whereas only one strain L65 isolated from hatchery pertained to ST3076, which indicated that resistant strains between the two farms was unrelated phylogenetically. Two clonal groups within ST48 were identified in breeding goose farm confirmed by SNP analysis (Figure S1).

\section{Transferability of bla NDM $-5_{5}$ Gene and the Underlying Mechanisms}

Conjugation assay was performed to investigate transferability of $b l a_{\mathrm{NDM}-5}$ gene, and transconjugants were successfully recovered from twelve donor strains (Table 1). It is noteworthy that the conjugation frequencies of $b l a_{\mathrm{NDM}-5}$-bearing plasmids were stable $\left(\sim 10^{-6}\right.$ per donor) (Table S2). S1-PFGE demonstrated that plasmids of ca. $46 \mathrm{~kb}$ in size could be observed in both donor strains and recipient strains except L53T, the transconjugant of L53, in which a plasmid of ca. $120 \mathrm{~kb}$ was found (Figure S2). The underlying molecular mechanism warrants further study. Two donor strains can transfer two plasmids into receipt strains (L103-1 and L103-2), enabling the two transconjugants resistant to multiple antibiotics (Table 1). The fact that all bla $a_{\mathrm{NDM}-5}$-bearing transconjugants carried a ca. $46 \mathrm{~kb}$ plasmid indicated bla $a_{\mathrm{NDM}-5}$ was located on a conjugative plasmid with a similar structure. To probe this hypothesis, complete genomes of six strains belonging to different clonal groups were obtained through short-read and long-read sequencing methods.

All bla $a_{\mathrm{NDM}-5}$-bearing plasmids from L37, L41-1, L53, L65, L100, L103-2 were almost identical (99\% query coverage and 99\% nucleotide identity) (Figure 1), with sizes ranging from 45,650 to $46,261 \mathrm{bp}$ (Table 2 ). The $b l a_{\mathrm{NDM}-5}$ gene was in the typical structure ISAba125-IS5-bla $a_{\mathrm{NDM}-5^{-}} b l e_{\mathrm{MBL}}-\operatorname{trpF}-d s b C$ IS26 found in IncX3 type plasmids. No other antimicrobial resistance genes were detected in these plasmids. These plasmids belonged to IncX3 type and showed 99\% nucleotide identity 
TABLE 2 | Basic information of the twelve bla $\mathrm{NDM}_{-5}$ positive $E$. coli strains revealed by WGS data.

\begin{tabular}{|c|c|c|c|c|c|c|c|c|c|c|}
\hline Strains & Species & $\begin{array}{l}\text { MLST } \\
\text { types }\end{array}$ & Source & $\begin{array}{l}\text { Conjugation } \\
\text { Transferability }^{\mathrm{a}}\end{array}$ & Resistance genes & $\begin{array}{l}\text { MinION } \\
\text { sequencing }\end{array}$ & $\begin{array}{l}\text { Plasmid names } \\
\text { (or replicons) }\end{array}$ & $\begin{array}{l}\text { Size } \\
\text { (bp) }\end{array}$ & $\begin{array}{l}\text { Number of } \\
\text { resistance } \\
\text { genes }\end{array}$ & $\begin{array}{r}\text { Accession } \\
\text { numbers }\end{array}$ \\
\hline \multirow[t]{3}{*}{ L37 } & Escherichia coli & ST-48 & Anal swab & + & 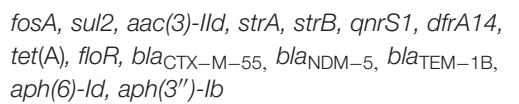 & + & pL37-2 (IncFIB, p0111) & 145704 & 9 & СР034590 \\
\hline & & & & & & & pL37-3 (IncX3) $)^{d}$ & 45650 & 1 & СР034591 \\
\hline & & & & & & & pL37-4 (IncFII) & 76559 & 3 & СР034592 \\
\hline \multirow[t]{3}{*}{$\llcorner 41-1$} & Escherichia coli & ST-48 & Feed & + & $\begin{array}{l}\text { strA, strB, sul2, floR, bla } \mathrm{CTX}-\mathrm{M}-64, \text { bla } \mathrm{ADM}_{\mathrm{ND}}-5 \\
\text { blaTEM-1A, tet(A) }\end{array}$ & + & $\begin{array}{l}\text { pL41-1-2 (IncFIB, } \\
\text { IncHIB, p0111) }\end{array}$ & 201021 & 8 & СР034728 \\
\hline & & & & & & & pL41-1-3 (IncFIB) & 111458 & 1 & СР034729 \\
\hline & & & & & & & pL41-1-4 (IncX3) & 46238 & 1 & СР034730 \\
\hline \multirow[t]{3}{*}{ L53 } & Escherichia coli & ST-48 & Water & + & 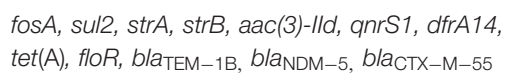 & + & pL53-2 (IncFIB, p0111) & 137848 & 9 & СР034745 \\
\hline & & & & & & & pL53-3 (IncFII) & 76642 & 3 & СР034756 \\
\hline & & & & & & & pL53-4 (IncX3) $)^{d}$ & 46259 & 1 & СР034757 \\
\hline \multirow[t]{2}{*}{ L65 } & Escherichia coli & ST-3076 & Feces & + & 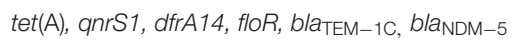 & + & pL65-2 (IncFIB, IncFII) & 145346 & 6 & СР034739 \\
\hline & & & & & & & pL65-9 (IncX3) ${ }^{d}$ & 46161 & 1 & СР034744 \\
\hline \multirow[t]{3}{*}{ L100 } & Escherichia coli & ST-48 & Anal swab & + & $\begin{array}{l}\text { strA, strB, sul2, floR, bla } \mathrm{CTX}-\mathrm{M}-64, \text { bla } \mathrm{TEM}-1 \mathrm{~A} \\
\text { bla } \\
\text { NDM-5, tet( } \mathrm{A})\end{array}$ & + & $\begin{array}{l}\text { pL100-2 (IncFIB, } \\
\text { IncHIB, p0111) }\end{array}$ & 202387 & 8 & СР034746 \\
\hline & & & & & & & pL100-3 (IncFIB) & 111458 & 1 & СР034747 \\
\hline & & & & & & & pL100-4 (IncX3) $)^{d}$ & 46261 & 1 & СР034748 \\
\hline \multirow[t]{6}{*}{ L103-2 } & Escherichia coli & ST8809 & Anal swab & + & 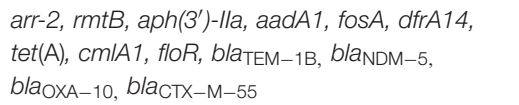 & + & pL103-2-2 (IncFIB) & 110210 & 0 & СР034844 \\
\hline & & & & & & & pL103-2-3 (IncFIB) & 102295 & 1 & СР034845 \\
\hline & & & & & & & pL103-2-4 (IncFII) & 100667 & 6 & СР034846 \\
\hline & & & & & & & pL103-2-5 (InCX3) ${ }^{d}$ & 46163 & 1 & СР034847 \\
\hline & & & & & & & pL103-2-6 (IncX1) & 13362 & 1 & СР034848 \\
\hline & & & & & & & pL103-2-7 (unknown) & 12606 & 6 & СР034849 \\
\hline L33 & Escherichia coli & ST-48 & Anal swab & + & $\begin{array}{l}\text { strB, strA, aac(3)-Ild, sul2, fosA, qnrS1, dfrA14, } \\
\text { tet(A), floR, bla } 1 \text { NDM-5, blaCTX-M-55, blaTEM-1B }\end{array}$ & - & $\operatorname{lncX} 3^{d}, p 0111$ & $46 \mathrm{~kb}^{\mathrm{C}}$ & 12 & Online $e^{b}$ \\
\hline L43-1 & Escherichia coli & ST-48 & Feces & + & $\begin{array}{l}\text { strA, strB, sul2, floR, bla } \mathrm{CTX}-\mathrm{M}-64, \text { bla } \mathrm{TEM}-1 \mathrm{~A} \\
\text { bla }_{\mathrm{NDM}}-5, \operatorname{tet}(\mathrm{A})\end{array}$ & - & $\begin{array}{l}\text { IncX3 }{ }^{d}, \text { p0111 } \\
\text { colRNAl }\end{array}$ & $46 \mathrm{~kb}$ & 8 & Online \\
\hline L56 & Escherichia coli & ST-48 & Water & + & $\begin{array}{l}\text { fosA, sul2, strA, strB, aac(3)-Ild, anrS1, dfrA14, } \\
\text { tet(A), floR, bla }\end{array}$ & - & $\operatorname{lnc} X^{d}, p 0111$ & $46 \mathrm{~kb}$ & 12 & Online \\
\hline L99 & Escherichia coli & ST-48 & Anal swab & + & $\begin{array}{l}\text { fosA, sul2, strA, strB, aac(3)-Ild, qnrS1, dfrA14, } \\
\text { tet(A), floR, bla }{ }_{\text {NDM-5, bla }} \text { CTX-M-55, bla } 1 \text { TEM-1B }\end{array}$ & - & $\operatorname{lnc} X 3^{d}, p 0111$ & $46 \mathrm{~kb}$ & 12 & Online \\
\hline L102 & Escherichia coli & ST-48 & Anal swab & + & $\operatorname{tet}(\mathrm{A})$, sul2, bla $a_{\mathrm{CTX}} \mathrm{M}-64, b / a_{\mathrm{NDM}-5}, \operatorname{str} B, \operatorname{str} A$ & - & $\operatorname{IncX} 3^{d}, p 0111$ & $46 \mathrm{~kb}$ & 6 & Online \\
\hline L103-1 & Escherichia coli & ST-48 & Anal swab & + & $\begin{array}{l}\text { strB, strA, aac(3)-Ild, sul2, fosA, gnrS1, dfrA14, } \\
\text { tet(A), floR, bla }\end{array}$ & - & $\begin{array}{l}\text { IncX3 }, \text { p0111 } \\
\text { colRNAl }\end{array}$ & $46 \mathrm{~kb}$ & 12 & Online \\
\hline
\end{tabular}

${ }^{a}$ Transference of plasmids carrying bla ${ }_{N D M-5}{ }^{b}$ The assembly results of six strains without complete genome sequences were deposited in figshare database for reference (https://figshare.com/articles/L33-L103-1/ 8044847). ${ }^{\circ}$ The length of bla NDM-5-bearing IncX3 plasmids in samples without MinION sequencing were infered from S1-PFGE. ${ }^{d}$ blanDM-5-bearing plasmid. 
A

pL37-3

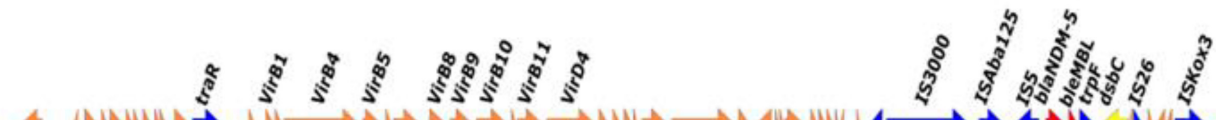

pNDM_MGR194

pNDM-QD28

pL100-4
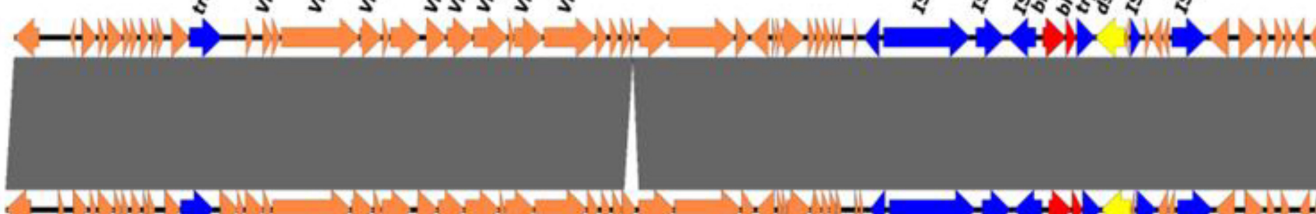

(1)

$\rightarrow$ -

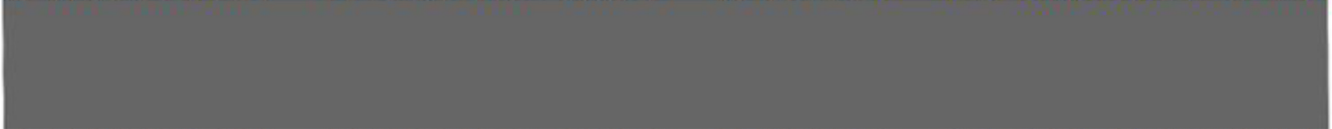

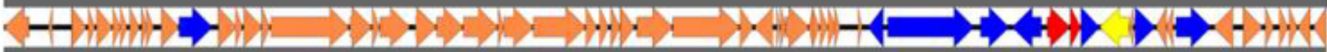

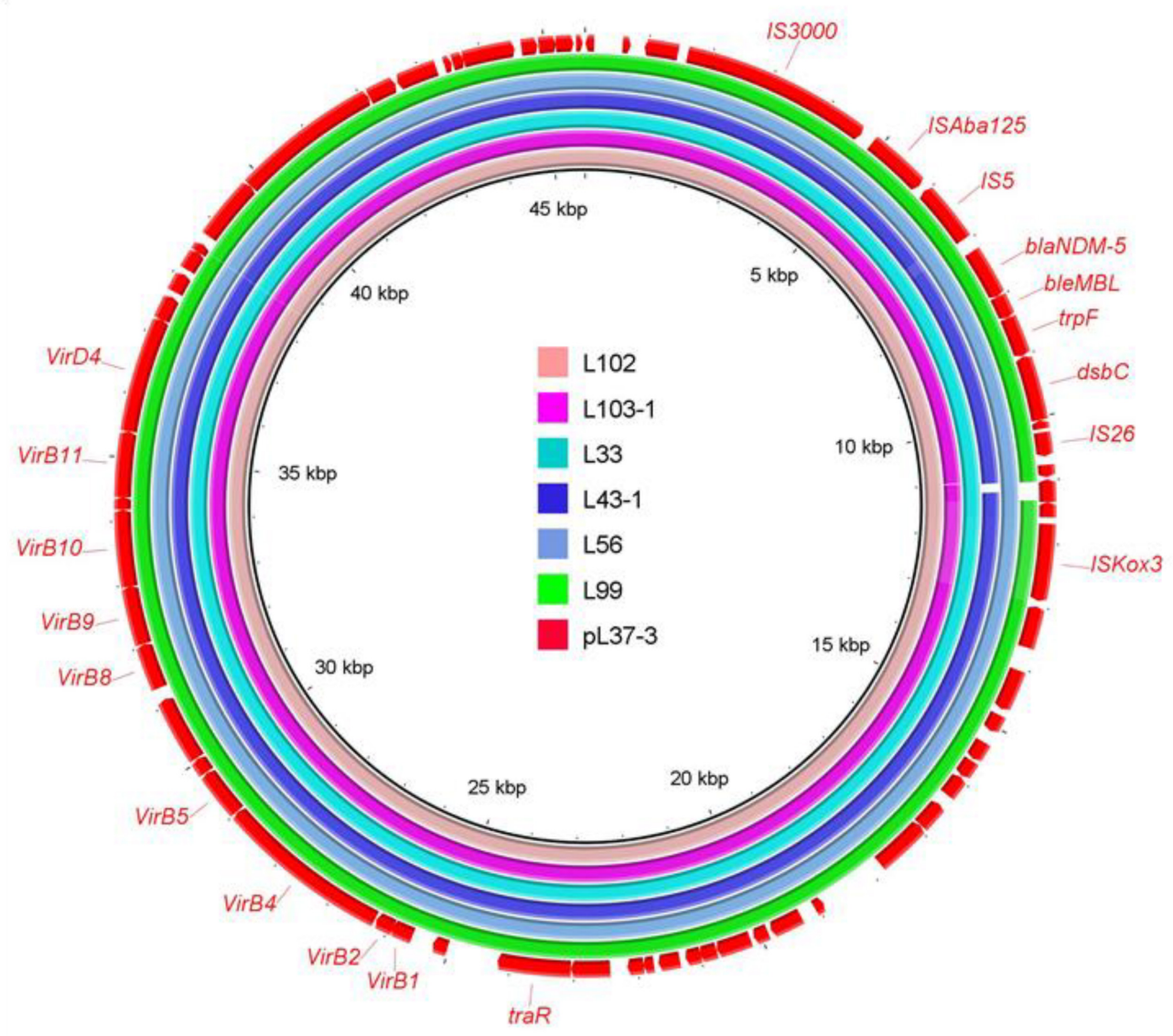

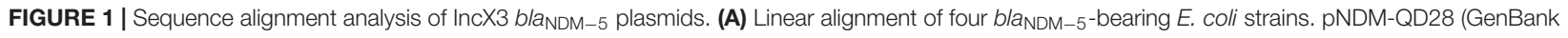

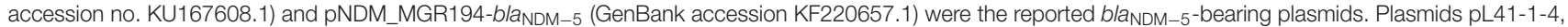

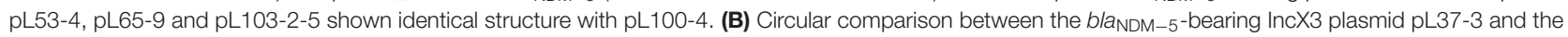
assembled contigs of other six blanDM-5 positive strains without MinlON data and based on Illumina data. 
with the first identified $b l a_{\mathrm{NDM}-5}$-harboring plasmid pNDMMGR194 of K. pneumoniae MGR-K194 in India (KF220657) (Krishnaraju et al., 2015) and pNDM-QD28 obtained from E. coli QD28 in China (KU167608) (Figure 1). The pNDMMGR194-like plasmids were reported in China frequently, which indicated IncX3 type plasmids were the epidemic vehicles mediating dissemination of the $b l a_{\mathrm{NDM}-5}$ in China (Krishnaraju et al., 2015; Li X. et al., 2018). The QD28 was the first identification of bla $a_{\mathrm{NDM}-5}$-carrying $E$. coli in the neonatal infection (Zhu et al., 2016). The bla $a_{\mathrm{NDM}-5}$-bearing IncX3 plasmid has been shown to be carried in several clinical isolates (Wailan et al., 2015; Zhang et al., 2016). The discovery of these $b l a_{\mathrm{NDM}-5}$-bearing plasmids in goose farm demonstrated the IncX3 plasmids accounted for widespread of $b l a_{\mathrm{NDM}-5}$ in this goose farm.

\section{Whole Genome Sequencing Analysis}

Analysis of whole genomes of the strains revealed the distribution of antibiotic resistance genes, replicon types and STs (Table 2). The twelve strains were divided into three clonal groups based on SNP analysis, and strains belonging to ST48 from both clonal group A and C were isolated from various sources including water, anal swabs and feces collected from the breeding goose farm, demonstrating the potential clonal spread of these $b a_{\mathrm{NDM}-5}$-bearing strains and transmission of bla $a_{\mathrm{NDM}-5}$-bearing plasmid among subtypes of ST48 in breeding goose farm (Figure S1). However, L65 (ST3076) isolated from goose hatchery and L103-2 (ST8809) obtained from breeding goose farm showed great difference from other strains (ST48) isolated from the breeding goose farm, suggesting that there was spread of $b a_{\mathrm{NDM}-5}$ mediated by the conjugative plasmid among different E. coli strains (Figure S1).

Apart from the $b a_{\mathrm{NDM}-5}$-bearing plasmids, other MDR plasmids were identified from the six complete genomes. L37 and L53 belonging to the same clonal group also carried other two plasmids, the IncFII plasmid (pL37-4, pL53-3) and the IncFIB/p0111 hybrid plasmid (pL37-2, pL53-2), respectively. A mosaic MDR region consisting of ISs and various resistance gene including qnrS1, floR, bla TEM-1B $_{\mathrm{B}}, \operatorname{sul} 2$, aac(3)-IId, aph(6)$I d$, $a p h\left(3^{\prime \prime}\right)-I b, d f r A 14$ and tet(A) was identified in IncFIB/p0111 hybrid plasmids (Figure S3). Two large similar plasmids (pL411-2 and pL100-2) over $200 \mathrm{~kb}$ were found in both L41-1 and L100 belonging to the same clonal group, and these two hybrid plasmids composing of IncFIB, IncHIB and p0111 replicons contained a MDR region (bla $a_{\mathrm{TEM}-1 \mathrm{~A}}, \operatorname{sul} 2$, floR, tet(A), aph(6)$I d$ and $\left.a p h\left(3^{\prime \prime}\right)-I b\right)$ dispersed among many insertion sequences. High insertion sequences abundance dispersed in plasmids may account for plasmid plasticity resulting in generation of hybrid plasmids. IS26 was proved to be involved in plasmid recombination (Wong et al., 2017). The formation of these two hybrid plasmids (pL41-1-2 and pL100-2) was probably related to insertion sequences (Figures S4, S5). A hybrid plasmid pL652 was found in L65, and pL65-2 was composed of IncFIB and IncFII replicons and the typical characteristic of this plasmid was a transfer region containing conjugative transfer genes, but no resistance genes were found (Figure S6).
Carbapenems are currently only approved for usage in humans and prohibited in animals. The emergence of bla $a_{\mathrm{NDM}-5}$ positive E. coli in animals and surrounding environments posed a great public health concern. Previously, there were reports of $b l a_{\mathrm{NDM}-5}$ positive strains found in various chicken and swine farms (Ho et al., 2018; Xiang et al., 2018). However, to the best of our knowledge, this was the first report of $b l a_{\mathrm{NDM}-5}$ positive strains of goose origin which was the important waterfowl in Jiangsu breeding industry. Further research revealed that ST48 bla $a_{\mathrm{NDM}-5}$ positive E. coli, as dominant type, underwent clone spread within goose farm. ST48 type E. coli is frequently associated to various $\beta$-lactamases, including ESBL and NDM (Liu et al., 2017; Said et al., 2017), thus we assumed that goose farming system could be a reservoir of $\beta$-lactamases genes. The occurrence of carbapenem-resistant strains in goose breeding farm was higher than that in goose hatchery, which may be due to the layout of the two farms. The breeding goose farm is an open space suitable for goose activities, facilitating transmission of MDR strains. The goose hatchery adopts a completely closed layout to protect the goslings from external environments, and few MDR bacteria contaminated the goose hatchery and prevalence of resistant strains was low.

IncX3 plasmids carrying various of bla $a_{\mathrm{NDM}}$ variants have been increasingly reported all over the world in recent years (Paskova et al., 2018; Xu and He, 2019). Previous study has proved the ability of $b l a_{\mathrm{NDM}}$-bearing IncX3 plasmid transfer to different Enterobacterial species at a wide range of temperatures (Wang Y. et al., 2018). Based on these facts, we believed that once the IncX3 plasmid carrying bla $a_{\mathrm{NDM}-5}$ was detected in goose farms, the risk of its widespread dissemination will be greatly increased.

Water is an essential element during goose growth, and water samples were collected from the river around the goose farm. The goose farm received and discharged river water without any purification measures, which may accelerate transfer of MDR bacteria. Bacteria encoding bla $a_{\mathrm{NDM}-5}$ was found in river (Almakki et al., 2017). Thus, river water has become a reservoir of drug-resistant bacteria. Apart from the feces and feed samples, water is another environmental sample detected positive for NDM-5-producing E. coli in this study. This indicated that contamination of the NDM5 producing E. coli between feces and water occurred in goose farm. Comprehensive surveillance of MDR bacteria in water surrounding the goose farm must be strengthened to understand the accurate contamination route. Since similar bla $a_{\mathrm{NDM}-5}$-bearing plasmids were always found in clinical settings and no carbapenem exposure existed in goose farms, this bla $a_{\mathrm{NDM}-5}$-bearing plasmid may derive from humans, further transfer and persist in goose farms to constitute a potential risk.

In conclusion, this study first identified the $b l a_{\mathrm{NDM}-5}$-bearing E. coli isolates in goose farms and its surroundings. Prevalence of NDM-5 producing E. coli posed a potential risk to public health. It is extremely urgent to reinforce the surveillance of resistance in the waterfowl system to curb the transmission or persistence of MDR bacteria. 


\section{DATA AVAILABILITY}

Publicly available datasets were analyzed in this study. This data can be found here: Refer to Table 2 for all accession numbers.

\section{AUTHOR CONTRIBUTIONS}

ZW and RL conceived and designed the study. ZL, YLi, and $\mathrm{XX}$ performed the study, analyzed the data, and prepared the manuscript. XX, YLiu, and RL revised the manuscript.

\section{FUNDING}

This work was supported by the National Key Research and Development Program of China (2016YFD0501310), National Natural Science Foundation of China (31872523

\section{REFERENCES}

Alikhan, N. F., Petty, N. K., Ben Zakour, N. L., and Beatson, S. A. (2011). BLAST ring image generator (BRIG): simple prokaryote genome comparisons. BMC Genomics 12:402. doi: 10.1186/1471-2164-12-402

Almakki, A., Maure, A., Pantel, A., Romano-Bertrand, S., Masnou, A., Marchandin, H., et al. (2017). NDM-5-producing Escherichia coli in an urban river in montpellier, France. Int. J. Antimicrob. Agents 50, 123-124. doi: 10.1016/j. ijantimicag.2017.04.003

CLSI, (2014). Performance Standards for Antimicrobial Susceptibility Testing: Twenty-fourth Informational Supplement M100-S24. Wayne, PA: CLSI.

Dallenne, C., Da Costa, A., Decre, D., Favier, C., and Arlet, G. (2010). Development of a set of multiplex PCR assays for the detection of genes encoding important beta-lactamases in Enterobacteriaceae. J. Antimicrob. Chemother. 65, 490-495. doi: $10.1093 /$ jac/dkp498

Ho, P. L., Wang, Y., Liu, M. C., Lai, E. L., Law, P. Y., Cao, H., et al. (2018). IncX3 epidemic plasmid carrying blaNDM-5 in Escherichia coli from swine in multiple geographic areas in China. Antimicrob. Agents Chemother. 62:e02295-17.

Hornsey, M., Phee, L., and Wareham, D. W. (2011). A novel variant, NDM-5, of the new delhi metallo-beta-lactamase in a multidrug-resistant Escherichia coli ST648 isolate recovered from a patient in the United Kingdom. Antimicrob. Agents Chemother. 55, 5952-5954. doi: 10.1128/AAC.05108-11

Kim, T. W., Kim, Y. H., Kim, S. E., Lee, J. H., Park, C. S., and Kim, H. Y. (2010). Identification and distribution of bacillus species in doenjang by whole-cell protein patterns and 16S rRNA gene sequence analysis. J. Microbiol. Biotechnol. 20, 1210-1214. doi: 10.4014/jmb.1002.02008

Krishnaraju, M., Kamatchi, C., Jha, A. K., Devasena, N., Vennila, R., Sumathi, G., et al. (2015). Complete sequencing of an IncX3 plasmid carrying bla(NDM-5) allele reveals an early stage in the dissemination of the bla(NDM) gene. Indian J. Med. Microbiol. 33, 30-38. doi: 10.4103/0255-0857.148373

Li, R., Xie, M., Dong, N., Lin, D., Yang, X., Wong, M. H. Y., et al. (2018). Efficient generation of complete sequences of MDR-encoding plasmids by rapid assembly of MinION barcoding sequencing data. Gigascience 7 , $1-9$.

Li, X., Fu, Y., Shen, M. Y., Huang, D. Y., Du, X. X., Hu, Q. F., et al. (2018). Dissemination of bla(NDM-5) gene via an IncX3-type plasmid among nonclonal Escherichia coli in China. Antimicrob. Resist. Infect. Control 7:59. doi: 10.1186/s13756-018-0349-6

Li, R. C., Ye, L. W., Wong, M. H. Y., Zheng, Z., Chan, E. W. C., and Chen, S. (2017). Evolution and comparative genomics of pAQU-like conjugative plasmids in vibrio species. J. Antimicrob. Chemother. 72, 2503-2506. doi: 10. 1093/jac/dkx193 and 31872526), the Natural Science Foundation of Jiangsu Province (BK20180900), and a Project Funded by the Priority Academic Program Development of Jiangsu Higher Education Institutions (PAPD). The Postgraduate Research and Practice Innovation Program of Jiangsu Province (Yangzhou University), XKYCX18_117 to ZL.

\section{ACKNOWLEDGMENTS}

We thank Jiayu Xiao and Xiaoyu Lu in Wang's Lab for sample collection.

\section{SUPPLEMENTARY MATERIAL}

The Supplementary Material for this article can be found online at: https://www.frontiersin.org/articles/10.3389/fmicb. 2019.02002/full\#supplementary-material

Liu, L., Feng, Y., Mcnally, A., and Zong, Z. Y. (2018). bla(NDM-21), a new variant of bla(NDM) in an Escherichia coli clinical isolate carrying bla(CTX-M-55) and rmtB. J. Antimicrob. Chemother. 73, 2336-2339. doi: 10.1093/jac/ dky226

Liu, Z., Wang, Y., Walsh, T. R., Liu, D., Shen, Z., Zhang, R., et al. (2017). Plasmid-mediated novel blaNDM-17 gene encoding a carbapenemase with enhanced activity in a sequence type 48 Escherichia coli strain. Antimicrob. Agents Chemother. 61:e002233-16.

Paskova, V., Medvecky, M., Skalova, A., Chudejova, K., Bitar, I., Jakubu, V., et al. (2018). Characterization of NDM-encoding plasmids from Enterobacteriaceae recovered from Czech Hospitals. Front. Microbiol. 9:1549. doi: 10.3389/fmicb. 2018.01549

Potter, R. F., D'souza, A. W., and Dantas, G. (2016). The rapid spread of carbapenem-resistant Enterobacteriaceae. Drug Resist. Updat. 29, 30-46. doi: 10.1016/j.drup.2016.09.002

Said, L. B., Hamdaoui, M., Jouini, A., Boudabous, A., Slama, K. B., Torres, C., et al. (2017). First detection of CTX-M-1 in extended-spectrum beta-lactamaseproducing Escherichia coli in seafood from Tunisia. J. Food Pro. 17, 1877-1881. doi: 10.4315/0362-028X.JFP-16-324

Sullivan, M. J., Petty, N. K., and Beatson, S. A. (2011). Easyfig: a genome comparison visualizer. Bioinformatics 27, 1009-1010. doi: 10.1093/bioinformatics/ btr039

Wailan, A. M., Paterson, D. L., Caffery, M., Sowden, D., and Sidjabat, H. E. (2015). Draft genome sequence of NDM-5-producing Escherichia coli sequence type 648 and genetic context of blaNDM-5 in Australia. Genome Announc. 3:e00194-15. doi: 10.1128/genomeA.00194-15

Walsh, T. R., Weeks, J., Livermore, D. M., and Toleman, M. A. (2011). Dissemination of NDM-1 positive bacteria in the New Delhi environment and its implications for human health: an environmental point prevalence study. Lancet Infect. Dis. 11, 355-362. doi: 10.1016/S1473-3099(11)70059-7

Wang, J., Yao, X., Luo, J., Lv, L. C., Zeng, Z. L., and Liu, J. H. (2018). Emergence of Escherichia coli co-producing NDM-1 and KPC-2 carbapenemases from a retail vegetable, China. J. Antimicrob. Chemother. 73, 252-254. doi: 10.1093/ jac/dkx335

Wang, R. B., Liu, Y. Q., Zhang, Q., Jin, L. Y., Wang, Q., Zhang, Y. W., et al. (2018). The prevalence of colistin resistance in Escherichia coli and Klebsiella pneumoniae isolated from food animals in China: coexistence of mcr-1 and bla(NDM) with low fitness cost. Int. J. Antimicrob. Agents 51, 739-744. doi: 10.1016/j.ijantimicag.2018.01.023

Wang, Y., Tong, M. K., Chow, K. H., Cheng, V. C., Tse, C. W., Wu, A. K., et al (2018). Occurrence of highly conjugative IncX3 epidemic plasmid carrying bla NDM in Enterobacteriaceae isolates in geographically widespread areas. Front. Microbiol. 9:2272. doi: 10.3389/fmicb.2018.02272 
Wick, R. R., Judd, L. M., Gorrie, C. L., and Holt, K. E. (2017). Unicycler: resolving bacterial genome assemblies from short and long sequencing reads. PLoS Comput. Biol. 13:e1005595. doi: 10.1371/journal.pcbi.100 5595

Wong, M. H. Y., Chan, E. W. C., and Chen, S. (2017). IS26-mediated formation of a virulence and resistance plasmid in Salmonella enteritidis. J. Antimicrob. Chemother. 72, 2750-2754. doi: 10.1093/jac/dkx238

Xiang, R., Zhang, A. Y., Ye, X. L., Kang, Z. Z., Lei, C. W., and Wang, H. N. (2018). Various sequence types of Enterobacteriaceae isolated from commercial chicken farms in china and carrying the blaNDM-5 gene. Antimicrob. Agents Chemother. 62:e0779-18. doi: 10.1128/AAC.00779-18

$\mathrm{Xu}$, J., and He, F. (2019). Characterization of a NDM-7 carbapenemaseproducing Escherichia coli ST410 clinical strain isolated from a urinary tract infection in China. Infect. Drug Resist. 12, 1555-1564. doi: 10.2147/IDR.S20 6211

Yang, R. S., Feng, Y., Lv, X. Y., Duan, J. H., Chen, J., Fang, L. X., et al. (2016). Emergence of NDM-5- and MCR-1-producing Escherichia coli clones ST648 and ST156 from a single muscovy duck (Cairina moschata). Antimicrob. Agents Chemother. 60, 6899-6902. doi: 10.1128/AAC.01 365-16

Yong, D., Toleman, M. A., Giske, C. G., Cho, H. S., Sundman, K., Lee, K., et al. (2009). Characterization of a new metallo-beta-lactamase gene, bla(NDM-1), and a novel erythromycin esterase gene carried on a Unique genetic structure in Klebsiella pneumoniae sequence type 14 from India. Antimicrob. Agents Chemother. 53, 5046-5054. doi: 10.1128/AAC.00774-09
Zhang, F., Xie, L., Wang, X., Han, L., Guo, X., Ni, Y., et al. (2016). Further spread of bla NDM-5 in Enterobacteriaceae via IncX3 plasmids in shanghai, China. Front. Microbiol. 7:424. doi: 10.3389/fmicb.2016.00424

Zhang, R., Li, J., Wang, Y., Shen, J., Shen, Z., and Wang, S. (2019). Presence of NDM in non-E. coli Enterobacteriaceae in the poultry production environment. J. Antimicrob. Chemother. 74, 2209-2213. doi: 10.1093/jac/ dkz193

Zhong, X., Droesch, J., Fox, R., Top, E. M., and Krone, S. M. (2012). On the meaning and estimation of plasmid transfer rates for surface-associated and well-mixed bacterial populations. J. Theor. Biol. 294, 144-152. doi: 10.1016/j. jtbi.2011.10.034

Zhu, Y. Q., Zhao, J. Y., Xu, C., Zhao, H., Jia, N., and Li, Y. N. (2016). Identification of an NDM-5-producing Escherichia coli sequence type 167 in a neonatal patient in China. Sci. Rep. 6:29934. doi: 10.1038/srep29934

Conflict of Interest Statement: The authors declare that the research was conducted in the absence of any commercial or financial relationships that could be construed as a potential conflict of interest.

Copyright (c) 2019 Liu, Xiao, Li, Liu, Li and Wang. This is an open-access article distributed under the terms of the Creative Commons Attribution License (CC BY). The use, distribution or reproduction in other forums is permitted, provided the original author(s) and the copyright owner(s) are credited and that the original publication in this journal is cited, in accordance with accepted academic practice. No use, distribution or reproduction is permitted which does not comply with these terms. 